\title{
Enhancement of Electrical Properties on ZnO: Al Thin Film due to Hydrogen Annealing and $\mathrm{SiO}_{2}$ Coating in Damp-heat Environment
}

\author{
Hao Chen, Yun-Hwan Jeong, and Choon-Bae Park* \\ School of Electrical, Electronic and Information Engineering, Wonkwang University, WRISS, 344-2 \\ Shinyong-dong, Iksan-si, Chonbuk 570-749, Republic of Korea
}

(Received February 18 2009, Accepted April 22 2009)

\begin{abstract}
The electrical stability of $\mathrm{ZnO}$ : Al thin films deposited on glass substrate by the RF magnetron sputtering method have been modified by a hydrogen annealing treatment and $\mathrm{SiO}_{2}$ protection layer. $\mathrm{AZO}$ thin films were deposited at room temperature and different $\mathrm{RF}$ powers of $50,100,150$, and $200 \mathrm{~W}$ to optimize the AZO film growth condition. The lowest value of resistivity of $9.44 \times 10^{-4} \Omega \mathrm{cm}$ was obtained at $2 \mathrm{mtorr}$, room temperature, and a power level of $150 \mathrm{~W}$. Then, the AZO thin films were annealed at $250-400^{\circ} \mathrm{C}$ for $1 \mathrm{~h}$ in hydrogen ambient. The minimum resistivity obtained was $8.32 \times 10^{-4} \Omega \mathrm{cm}$ as-annealed at $300^{\circ} \mathrm{C}$. The electrical properties were enhanced by the hydrogen annealing treatment. After a $72 \mathrm{~h}$ damp-heat treatment in harsh conditions of a water steam at 110 ${ }^{\circ} \mathrm{C}$ for four representative samples, a degradation of electrical properties was observed. The sample of hydrogen-annealed $\mathrm{AZO}$ thin films with $\mathrm{SiO}_{2}$ protection layer showed a slight degradation ratio (17\%) of electrical properties and a preferable transmittance of $90 \%$. The electrical stability of AZO thin films had been modified by hydrogen annealing treatment and $\mathrm{SiO}_{2}$ protection layer.
\end{abstract}

Keywords: Hydrogen annealing, $\mathrm{SiO}_{2}$ protection layer, Electrical stability, Damp-heat environment

\section{INTRODUCTION}

Transparent conductive oxide (TCO) films such as indium tin oxide (ITO) and zinc oxide ( $\mathrm{ZnO}$ ), heavily doped with n-type dopants, have been extensively applied to thin film solar cells as front electrodes because of their high transmittance and good electrical properties. In particular, $\mathrm{Al}$-doped $\mathrm{ZnO}(\mathrm{AZO})$ films are regarded as good substitutes for ITO films. AZO thin films show high transparency in the visible wavelength range, high electrical conductivity, high thermal stability, and low cost comparable to those of ITO thin films[1,2]. Magnetron-sputtered AZO thin films are used in front contact windows for silicon and $\mathrm{Cu}(\mathrm{In}$, Ga) $\mathrm{Se}_{2}$ (CIGS)-based thin film solar cells[3]. Good long-term stability of solar cells in harsh outdoor conditions is necessary to realize successful commercialization. However, the electrical properties of AZO thin films are degraded when films are exposed to air ambient[1], which restricts the use of AZO films for solar cells. Researchers have done some work on improving the ability to resist the degradation of film conductivity and transmission during the preparation of AZO thin films[3]. It was reported that thermally-treated AZO thin films in hydrogen ambient could improve electrical conductivity[1] as well as increase stability in air exposure[4]. It is known that $\mathrm{SiO}_{2}$ thin films find wide application for anti-reflective coatings, such as protective layers, and have been applied in various ways to improve the aging of photovoltaic devices as encapsulated coatings $[5,6]$. However, few works have been reported on the stability of the $\mathrm{AZO}$ thin films with $\mathrm{SiO}_{2}$ film coating as a protective layer. In this paper, the electrical properties of $\mathrm{AZO}$ thin films with a $\mathrm{SiO}_{2}$ protective layer are investigated, which may be helpful in improving the aging of encapsulated-modules for long-term stability of solar cells in harsh outdoor conditions.

*Author to whom corresponding should be addressed: electronic mail: cbpark@wonkwang.ac.kr
We used a damp-heat environment as a module of harsh outdoor conditions to test the electrical stability of AZO thin films with or without hydrogen annealing treatment and a $\mathrm{SiO}_{2}$ protective layer. We found that a hydrogen annealing treatment enhanced the electrical characteristics of AZO thin films, and the $\mathrm{SiO}_{2}$ protection layer apparently water from penetrating into the AZO thin films, thereby resisting the degradation of film conductivity. Thus, the electrical stability of AZO thin films can be improved.

\section{EXPERIMENTS}

The AZO thin films and $\mathrm{SiO}_{2}$ protection layer were deposited by RF magnetron sputtering with a base pressure of $8 \times 10^{-6}$ Torr at room temperature. AZO thin films were deposited on Corning 1737 glass substrates with a $\mathrm{ZnO}$ : $\mathrm{Al}_{2} \mathrm{O}_{3} \quad(2 \mathrm{wt} \%)$ ceramic target. The substrates were sequentially ultrasonically cleaned in acetone, alcohol, and de-ionized water, and dried with nitrogen gas. During the sputtering, the working pressure was maintained at 2 mtorr with $\mathrm{Ar}$ ambient, and the RF power was controlled in the range of 50-200 W. The pre-sputtering and deposition times were $10 \mathrm{~min}$ and $60 \mathrm{~min}$, respectively. The $\mathrm{SiO}_{2}$ protective layer was deposited on the AZO thin films using a glass target. RF power and deposition time was $50 \mathrm{~W}$ and $2 \mathrm{hrs,}$ respectively. Other conditions were the same as for the AZO thin films. Annealing treatments were carried out in ambient atmospheric hydrogen for $1 \mathrm{hr}$ at a temperature of $250-400{ }^{\circ} \mathrm{C}$. The details of deposition and annealing conditions of the AZO thin films are listed in Table 1, and the details of deposition conditions for the $\mathrm{SiO}_{2}$ protection layer are listed in Table 2.

The electrical properties were evaluated by Hall measurement. Cross-section morphologies were observed by scanning electron microscopy (SEM). Four representative samples were selected for the electrical stability test: A: as-deposited AZO thin films; B: hydrogen-annealed AZO 
Table 1. Conditions of AZO thin film deposition on glass substrate by RF magnetron sputtering and annealing.

\begin{tabular}{ll}
\hline Parameters & Detailed conditions \\
\hline substrate & Coring glass 1737 \\
target & $\mathrm{ZnO}: \mathrm{Al}_{2} \mathrm{O}_{3}(2 \mathrm{wt} \%)$ \\
base pressure & $8 \times 10^{-6} \mathrm{Torr}$ \\
working pressure & $2 \mathrm{mTorr}$ \\
growth temperature & $\mathrm{RT}$ \\
ambient gas & $\mathrm{Ar}$ \\
RF power & $50,100,150,200 \mathrm{~W}$ \\
pre-sputtering time & $10 \mathrm{~min}$ \\
deposition time & $1 \mathrm{hr}$ \\
\hline & $\mathrm{H}_{2}$ \\
annealing & $10 \mathrm{Torr}$ \\
& $250,300,350,400^{\circ} \mathrm{C}$ \\
& $1 \mathrm{hr}$ \\
\hline
\end{tabular}

Table 2. Conditions of $\mathrm{SiO}_{2}$ protection layer deposition on $\mathrm{AZO}$ thin film by RF magnetron sputtering.

\begin{tabular}{ll}
\hline Parameters & Detailed Conditions \\
\hline substrate & AZO thin films on the glass \\
target & Glass \\
base pressure & $8 \times 10^{-6}$ Torr \\
working pressure & $2 \mathrm{mTorr}$ \\
growth temperature & $\mathrm{RT}$ \\
ambient gas & $\mathrm{Ar}$ \\
RF power & $50 \mathrm{~W}$ \\
pre-sputtering time & $10 \mathrm{~min}$ \\
deposition time & $2 \mathrm{hrs}$
\end{tabular}

thin films; $\mathrm{C}$ : as-deposited $\mathrm{AZO}$ thin films with $\mathrm{SiO}_{2}$ protection layer; and D: hydrogen-annealed AZO thin films with $\mathrm{SiO}_{2}$ protection layer. All of these samples were exposed in the damp-heat environment at a temperature of $100{ }^{\circ} \mathrm{C}$ in a water steam for $72 \mathrm{~h}$, and the resistance values of the samples were recorded once every $24 \mathrm{~h}$ to analyze the evolution of the electrical characteristics. The optical transmittance of the damp-heat treated samples were measured in the range of $300-1100 \mathrm{~nm}$ by a spectrophotometer.

\section{RESULTS AND DISCUSSION}

First, we investigated the influence of deposition power on the electrical properties of as-deposited AZO thin films.
Figure 1 shows the deposition RF power. The deposition rate was found to be directly proportional to the deposition RF powers from $50 \mathrm{~W}$ to $200 \mathrm{~W}$. An increase in deposition rate with RF power results from more target atoms being ejected from the source when RF power is increased[7-9]. The thin film resistivity decreased from $19.5 \times 10^{-4}$ to $9.44 \times 10^{-4} \Omega \mathrm{cm}$ as the RF power increased from 50 to 150 $\mathrm{W}$, and thereafter the resistivity increased slightly at $200 \mathrm{~W}$. Figure 2 illustrates the carrier concentration and Hall mobility of AZO films as a function of RF power. Both carrier concentration and Hall mobility increased as the RF power was increased up to $150 \mathrm{~W}$. Thereafter, they decreased at a power of $200 \mathrm{~W}$. This characteristic can be understood from the fact that the probability of trapped $\mathrm{Al}$ or $\mathrm{Zn}$ increased with the increase in RF power[10]. The lowest resistivity of $9.44 \times 10^{-4} \Omega \mathrm{cm}$ was achieved when the AZO thin films were deposited with RF power of $150 \mathrm{~W}$.

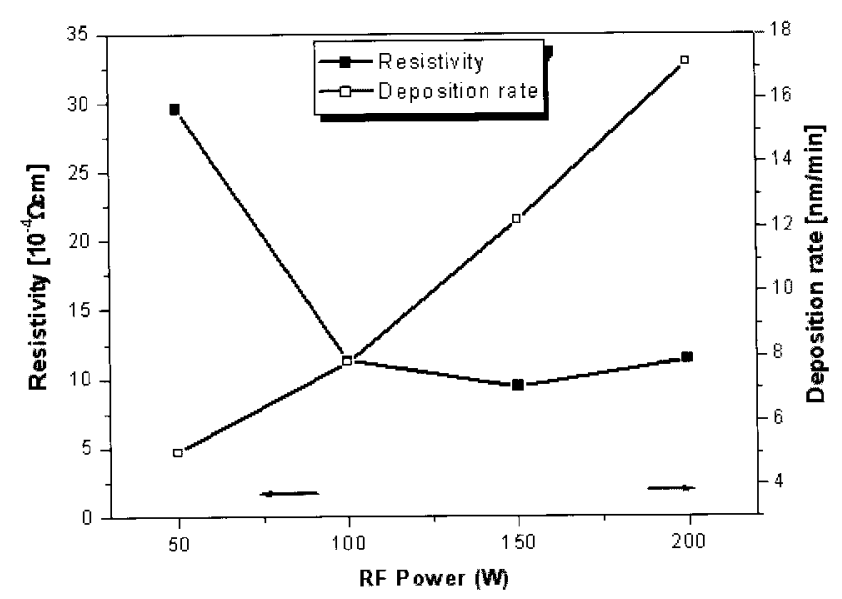

Fig. 1. Deposition rate and resistivity of AZO thin films as a function of RF power.

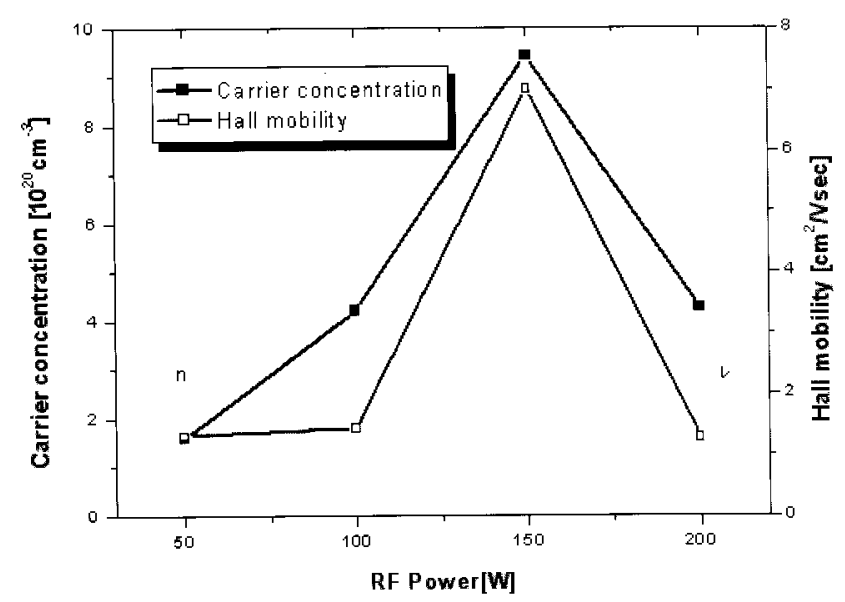

Fig. 2. Carrier concentration and Hall mobility of AZO thin films as a function of RF power.

The deposited AZO films were thermally treated in ambient hydrogen. Changes in the electrical characteristics of the hydrogen-annealed AZO films were investigated as a function of annealing temperature, as shown in Fig. 3. 


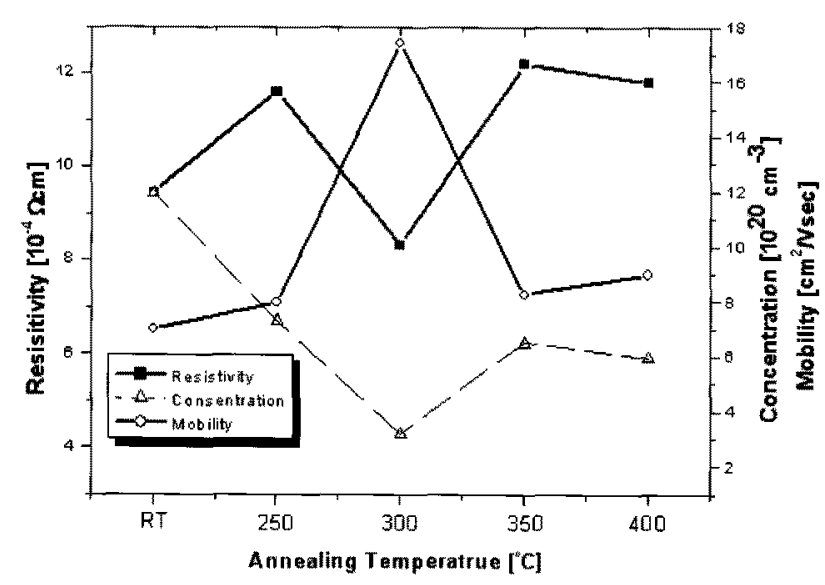

Fig. 3. Resistivity, carrier concentration, and Hall mobility of AZO thin films as a function of the hydrogen annealing temperature.

Hydrogen annealing treatment improved the electrical characteristics of the AZO films, and the resistivity of the film annealed at $300^{\circ} \mathrm{C}$ was as low as $8.32 \times 10^{-4} \Omega \mathrm{cm}$. The resistivity $\rho$ is inversely proportional to carrier concentration $\mathrm{n}$ and mobility $\mu[11]$ :

$$
\rho=\frac{1}{\text { ne } \mu}
$$

The carrier concentration decreased and the mobility increased sequentially as the annealing temperature from 250 to $300{ }^{\circ} \mathrm{C}$, but the degree of mobility increased to a greater than the carrier concentration decreased, which lead to the resistivity decreasing accordingly. Hence, the faster increase in mobility resulted in a major contribution to electrical conductivity. Due to the polycrystalline nature of the film, we assumed that as-deposited films have an excess of oxygen chemisorbed at grain boundaries and other defects; for example, at oxygen vacancies and metal interstitials [3], which reduce the mobility of the AZO films [3]. Moreover, the chemisorbed oxygen forms depletion regions; i. e., the barrier near the grain boundary surfaces, which causes a decrease in the mobility of the AZO films [1]. Desorption of oxygen from the boundaries should occur while the films are annealing in the hydrogen atmosphere; therefore, the mobility of electrons increases. At the same time, some oxygen diffuses to oxygen vacancies in the films, which reduced the carrier concentration. When the annealing temperature is larger than $300^{\circ} \mathrm{C}$, we can see the reverse trend in the electron mobility and the carrier concentration.

The $\mathrm{SiO}_{2}$ protection layer was deposited on the $\mathrm{AZO}$ thin films to promote the electrical stability of AZO film. Figure 4 shows a cross-section FE-SEM image of the $\mathrm{SiO}_{2}$ protection layer that deposited on the AZO thin film. This $\mathrm{SiO}_{2}$ protection layer presented a compact microstructure. We note that the compact structure of $\mathrm{SiO}_{2}$ can prevent degradation of AZO thin film from water vapor in air, which is helpful in enhancing the electrical stability of AZO thin films. The results of the electrical stability test confirmed this point of view. Figure 5 shows the resistance increase ratio of four representative samples $(A, B, C$, and D) as a function of the exposed time in the damp-heat environment. The samples were exposed in the damp-heat environment after $72 \mathrm{~h}$; it can be seen that the resistance increase of all films varies in the range of $17 \%-72 \%$. Sample D (hydrogen-annealed AZO thin films with $\mathrm{SiO}_{2}$ protection layer) showed the smallest increase of resistance, while sample A (as-deposited AZO thin films) was affected the most by the damp-heat environment. The degradation of electrical properties can be explained as follows: in the damp-heat environment, oxygen and water molecules penetrate into the films via defect paths[9]. So, the width and height of grain boundary barriers are increased. The water existing in a grain boundary could strengthen the effect of grain boundary scattering and led to enhanced capture of free carriers, thus decreasing the carrier concentration and the mobility[3]. Comparing samples $A$ and $\mathrm{B}$, hydrogen annealing treatment improved the electrical stability of the AZO thin films. Hydrogen annealed $\mathrm{AZO}$ thin films with a $\mathrm{SiO}_{2}$ protection layer higher electrical stability than thin films with only an $\mathrm{SiO}_{2}$ protection layer, as shown by samples $\mathrm{C}$ and $\mathrm{D}$. This indicates that the hydrogen annealing process resulted in desorption of weakly adsorbed oxygen species on the grain boundaries[1]. Moreover, the advantage of the $\mathrm{SiO}_{2}$ protection layer which the electrical stability of AZO thin films has apparently been shown by samples $\mathrm{C}$ and $\mathrm{D}$ apparently. Thus, the $\mathrm{SiO}_{2}$ protection layer effectively prevented the oxygen and water molecules from penetrating into the AZO thin films.

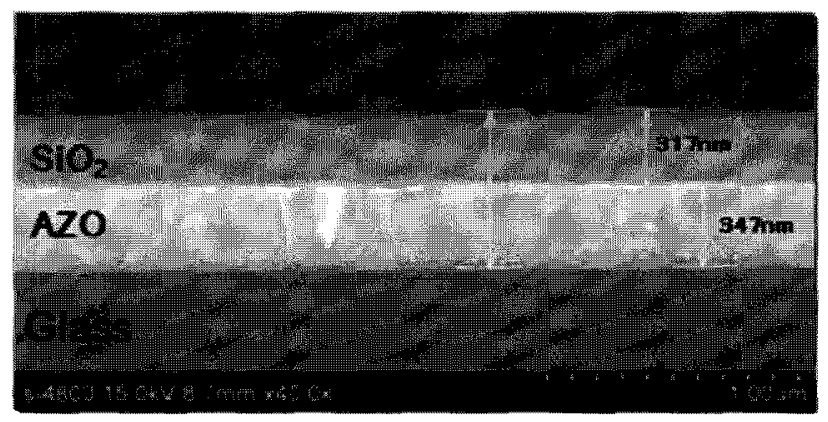

Fig. 4. Cross-sectional FE-SEM image of $\mathrm{SiO}_{2}$ protection layer deposited on AZO thin film.

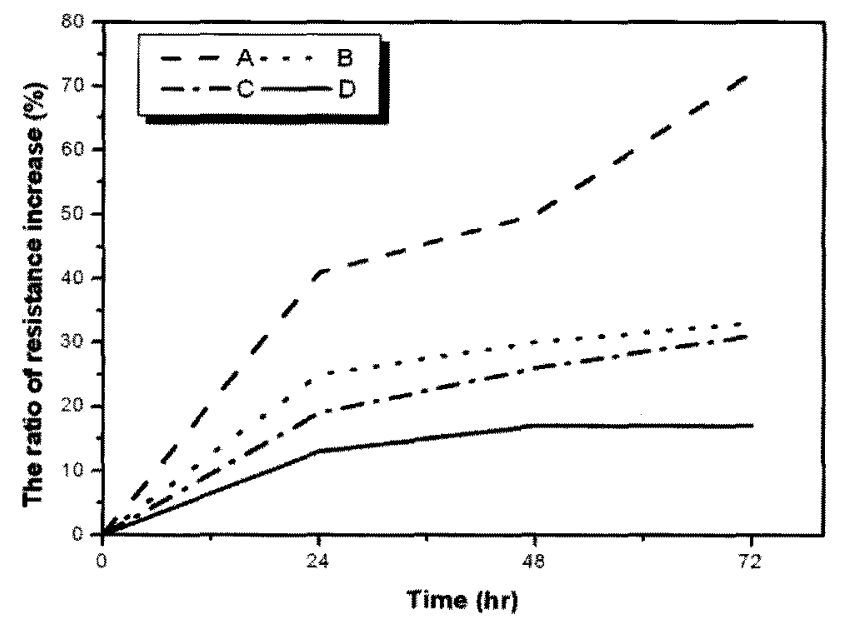

Fig. 5. Ratio of resistance increase for four representative films (A: samples as-deposited $\mathrm{AZO}$ thin films; $\mathrm{B}$ : hydrogen-annealed $\mathrm{AZO}$ thin films; $\mathrm{C}$ : as-deposited AZO thin films with $\mathrm{SiO}_{2}$ protection layer; and D: hydrogen-annealed $\mathrm{AZO}$ thin films with $\mathrm{SiO}_{2}$ protection layer) as a function of damp-heat environment exposure time. 


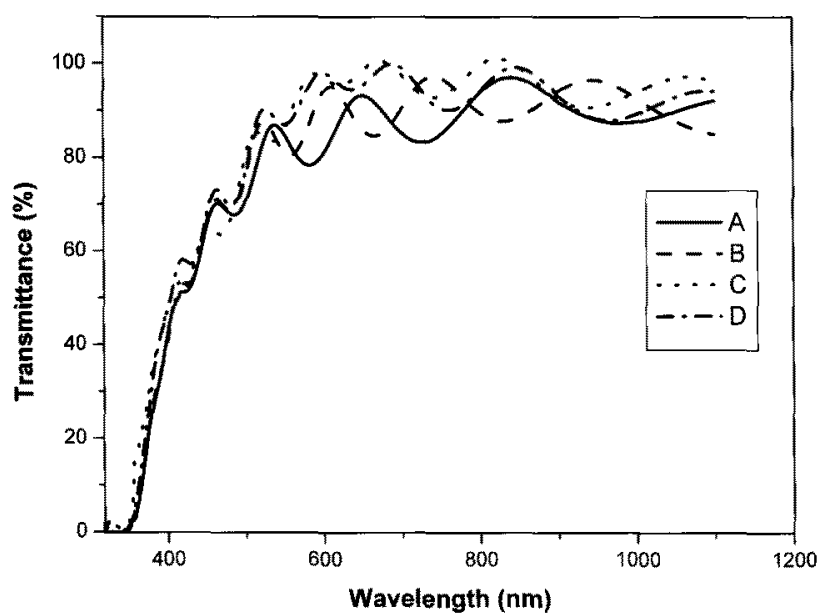

Fig. 6. Transmittance for four AZO films. (A: samples as-deposited AZO thin films, B: hydrogen-annealed AZO thin films, $\mathrm{C}$ : as-deposited AZO thin films with $\mathrm{SiO}_{2}$ protection layer, $\mathrm{D}$ : hydrogen-annealed $\mathrm{AZO}$ thin films with $\mathrm{SiO}_{2}$ protection layer)

The transmittance of the samples (A, B, C and D) for 72 $h$ of damp-heat treatment was measured at room temperature and the spectra are shown in Fig. 6. The average optical transmittance was above $85 \%$ in the wavelength range of $400-1100 \mathrm{~nm}$ for all samples, which is suitable to silicon solar cells. The sample D (hydrogenannealed $\mathrm{AZO}$ thin films with $\mathrm{SiO}_{2}$ protection layer) showed a preferable transmittance of $90 \%$. It suggests that $\mathrm{SiO}_{2}$ protection layer also improves the transmission of AZO films. Moreover, the transmittance edge shifts to shorter wavelength $(\sim 312 \mathrm{~nm})$ for the hydrogen annealed AZO thin films (sample B and D) compared with the sample A. This phenomenon is due to the Burstein-Moss effect that the optical band gap is widened with increasing donor concentration due to the filling of conduction band by increase of electron carriers.

\section{CONCLUSION}

Electrical properties were enhanced due to the removal of the absorbed oxygen species at the grain boundaries by the hydrogen annealing process. Resistivity decreased from $9.44 \times 10^{-4} \Omega \mathrm{cm}$ to $8.32 \times 10^{-4} \Omega \mathrm{cm}$ after annealing in a hydrogen atmosphere for $1 \mathrm{~h}$ at $300^{\circ} \mathrm{C}$. An RF magnetron- sputtered $\mathrm{SiO}_{2}$ protection layer on AZO thin films exhibited compact structure, which was an advantage in retarding corrosion from the external environment. After $72 \mathrm{~h}$ damp-heat treatment in harsh conditions in a water steam at $110^{\circ} \mathrm{C}$ for four representative samples, degradation of electrical properties was observed. The average optical transmittance for all the samples was above $85 \%$ in wavelength region of $400-1100 \mathrm{~nm}$, which is suitable to the silicon solar cell. The sample of hydrogen-annealed AZO thin film with $\mathrm{SiO}_{2}$ protection layer showed a preferable transmittance of $90 \%$ and the faintish degradation ratio $(17 \%)$ of electrical properties, which was much better than other films. The electrical stability of AZO thin films had been modified by hydrogen annealing treatment and $\mathrm{SiO}_{2}$ protection layer, implying that the hydrogen annealed AZO thin film with $\mathrm{SiO}_{2}$ protection layer is applicable to the silicon solar cell without any reduction of optical transmittance.

\section{ACKNOWLEDGMENTS}

This work was supported by the Small and Medium Business Administration (SMBA) of South Korea through the Enterprise Attached Research Institute.

\section{REFERENCES}

[1] B.-Y. Oh, M.-C. Jeong, and J.-M. Myoung, Appl. Surf. Sci. 253, 7157 (2007).

[2] E.-M. Jin, E.-C. Shin, T.-W. Kim, and C.-B. Park, J. of KIEEME(in Korean) 20, 357 (2007).

[3] W. Lina, R. Maa, J. Xueb, and B. Kanga, Sol. Energy Mater. Sol. Cells. 91, 1902 (2007).

[4] S. H. Lee, T. S. Lee, K. S. Lee, B. Cheong, X. D. Kim, and W. M. Kim, J. Phys. D: Appl. Phys. 41, 095303 (2008).

[5] C. Guill "enU, A. Morales, and J. Herrero, Surf. Coat. Technol. 132, $31(2000)$

[6] C. Ballifa, J. Dickerb, D. Borcherta, and T. Hofmannc, Sol. Energy Mater. Sol. Cells. 82, 331 (2004).

17] D. Song, Appl. Surf. Sci. 254,4171 (2008)

[8] D.-J. Kwak, M.-W. Park, and Y.-M. Sung, Vacuum 83, 113 (2008).

[9] Y.-H. Jeong, H.-J. Jin, and C.-B. Park, J. of KIEEME(in Korean) 21, 863 (2008).

[10] W. J. Jeong, S. K. Kim, and G. C. Park, Thin Solid Films 506-507, $180(2006)$

[11] W. Liu, G. Du, Y. Sun, Y. Xu, T. Yang, X. Wang, Y. Chang, and F. Qiu, Thin Solid Films 515, 3057 (2007.) 